\title{
CONSIDERAÇÕES INICIAIS SOBRE A "NOVA ECONOMIA DO PROJETAMENTO”
}

Elias Khalil Jabbour ${ }^{1}$ Alexis Toríbio Dantas ${ }^{2}$ Carlos José Espíndola ${ }^{3}$

Resumo: O objetivo deste artigo é demonstrar que a transformação do "socialismo de mercado" em uma Nova Formação Econômico-Social (NFES) vai além de um fenômeno localizado na China. Trata de uma nova economia que o processo histórico está desenhando em meio, e a partir, do processo de financeirização, agressividade imperialista, do surgimento/espraiamento de novos paradigmas produtivos e tecnológicos e das novas e superiores formas de planificação sendo gestadas e executadas em larga escala na China. A esta nova economia - que se desenvolve na esteira do processo de transição e mudança do modo de produção (MP) dominante - nomeamos de "Nova Economia do Projetamento", inspirada na Economia do Projetamento elaborada por Ignacio Rangel no final dos anos de 1950. O ponto de partida é o materialismo histórico de Marx e Engels acrescido de todo acervo teórico já existente elaborado ao longo do tempo pelo campo da heterodoxia econômica. Trata-se de uma exigência que a história coloca aos economistas, pois a própria ciência econômica muda e varia com o MP que, por seu turno, está em constante transformação.

Palavras-chave: China. Nova Economia do Projetamento. Socialismo de mercado. Formação econômico-social. Teoria econômica. Modo de produção.

\section{INITIAL CONSIDERATIONS ON THE "NEW DESIGN ECONOMY"}

Abstract: The purpose of this article is to demonstrate that the transformation of "market socialism" into a New Socio-Economic Formation (NSEF) goes beyond a phenomenon located in China. It is about a new economy that the historical process is drawing in and out of the process of financialization, imperialist aggressiveness, the emergence / spreading of new productive and technological paradigms and the new and superior forms of planning being developed and executed in large in China. To this new economy - which develops in the wake of the transition process and change of the dominant mode of production (MP) - we call it the New Theory of Projection, inspired by the Economics of Projection developed by Ignacio Rangel in the late 1950s. of departure is the historical materialism of Marx and Engels plus any existing theoretical collection elaborated over time by the field of economic heterodoxy. This is a demand that history places on economists, since economic science itself changes and changes with the MP, which in turn is constantly changing.

Keywords: China. New Projection Economics. Market socialism. Economic-social formation. Economic theory. Mode of production.

\footnotetext{
1 Universidade do Estado do Rio de Janeiro, Faculdade de Ciências Econômicas, Rio de Janeiro, Brasil, eliasjabbour@terra.com.br, 0000-0003-0946-1519

Departamento, Cidade, País, email@email.br, https://orcid.org/0000-0002-1825-0097

2 Universidade do Estado do Rio de Janeiro, Faculdade de Ciências Econômicas, Rio de Janeiro, Brasil, alexis.dantas@gmail.com, 0000-0002-4742-7197

${ }^{3}$ Universidade Federal de Santa Catarina, Departamento de Geociências, Florianópolis, Brasil, carlos.espindola@ufsc.br, 0000-0002-5857-6067
} 


\title{
CONSIDERACIONES INICIALES SOBRE LA "NUEVA ECONOMÍA DEL PROYECTAMIENTO"
}

Resumen: El objetivo de este artículo es demostrar que la transformación del "socialismo de mercado" en una Nueva Formación Económico-Social (NFES) va más allá de un fenómeno localizado en China. Se trata de una nueva economía que el proceso histórico está desarrollando en medo a, y a partir del proceso de financiarización, agresividad imperialista, surgimiento/expansión de nuevos paradigmas productivos y tecnológicos, de las formas nuevas y superiores de planificación siendo gestadas y ejecutadas en gran escala, en China. A esta nueva economía, que se desarrolla en la estera del proceso de transición y cambio del modo de producción dominante (MP), la denominamos como la "Nueva Economía del Proyectamiento" y se inspira en la Economía del Proyectamiento elaborada por Ignacio Rangel, a fines de 1950. El punto de partida es el materialismo histórico de Marx y Engels con el agregado de todo el acervo teórico ya existente elaborado a lo largo del tiempo por el campo de la heterodoxia económica. Se trata de una exigencia que la historia demanda de los economistas, pues la propia ciencia económica cambia y varía con el MP que, a su vez, está en constante transformación.

Palabras clave: China. Nueva Economía del Proyectamiento. Socialismo de mercado. Formación económico-social. Teoría económica. Modo de producción.

\begin{abstract}
Fora da história, a economia se reduz à lógica, à dialética e a uma gnoseologia, que tanto são econômicas como físicas ou químicas. Não existe, pois, economia 'pura' [...]. A ciência econômica, porém, varia com o modo de produção e este muda ininterruptamente. (...). É admitir que o homem varie em seu ser e em sua consciência segundo a realidade geral, social e telúrica em que surge e cresce. (...). Devemos ser avessos à incorporação acrítica seja de modelos importados (marxistas ou não), seja de modismos acadêmicos. O que importa é como conhecer a sociedade concreta se comporta em sua vida econômica (Ignacio Rangel, [1957] 2005, p. 287-288)
\end{abstract}

\section{INTRODUÇÃO}

Os 200 anos de nascimento de Karl Marx foram marcados por debates em todos os cantos do planeta, sobretudo na China onde uma verdadeira blitz de propaganda massiva do marxismo foi executada. Além disso, o presidente chinês, Xi Jinping estarreceu $\mathrm{o}$ mundo com um discurso onde não apenas reafirmou 0 marxismo como a ideologia guia do Estado chinês: nomeou Karl Marx "como o maior pensador de todos os tempos" (2018, p. 83). Ou seja, após mais de 20 anos de proclamação do "fim da história" e da morte definitiva do marxismo, não é nada trivial 
o gesto - e o recado - corajoso do chefe de Estado do país pronto a assumir a vanguarda da humanidade. Ainda segundo o presidente chinês ${ }^{4}$ :

The ability of the whole Party to solve the practical problems of contemporary China with the basic principles of Marxism should be enhanced. (...) More efforts should be made to develop Marxism in the 21st century and in contemporary China, and write a new chapter of adapting Marxism to the Chinese context

A postura de afirmação e do reconhecimento do papel do marxismo no passado, no presente e no futuro da China, posta de forma clara por Xi Jinping, não encontra eco entre a ampla maioria dos marxistas que rejeitam o caráter socializante do processo em curso no gigante asiático. O conteúdo da maioria absoluta dos estudos sobre a China que jorram aos milhares, sob forma de dissertações ou teses de doutorado e nas prateleiras de livrarias, não conseguem atentar para o fato de que no real está ocorrendo naquele país a construção de um edifício original, onde surgem e ressurgem elementos e instituições de diferentes épocas históricas.

Intentamos fugir da superfície. A única razão desse gigantesco processo em andamento na China é observa-lo como parte da história da civilização humana, não se trata de um milagre; muito menos um acaso. Munidos com uma visão historicista e observando além do horizonte, é perceptível a ocorrência de um processo histórico onde uma nova economia está surgindo, tendo na China seu núcleo de ocorrência sob o acicate do chamado "socialismo de mercado". Processo semelhante marcou o século XX com uma economia desenhada nos marcos do desenvolvimento do capital financeiro, o keynesianismo e a planificação soviética.

A esta economia, que se desenvolveu no século passado, Ignacio Rangel a nomeou de Economia do Projetamento ${ }^{5}$. A citada economia seria consequência tanto da curva descendente do capitalismo na década de 1930 quanto do surgimento de novos paradigmas concebidos por três ocorrências: 1) a Revolução Russa, que tornou possível o planejamento econômico; 2) o desenvolvimento da economia monetária e 3) do keynesianismo e o consenso criado em torno dele. Muda a face do sistema e as lógicas que espelhavam o processo real.

Subentende-se que a problemática econômica do capitalismo muda radicalmente quando o sistema passa do ramo ascendente da curva para o descendente (Rangel, 2005 [1957], p. 290). Em outras palavras, é proscrito o "método direto", fazendo perder completo sentido as concepções signatárias tanto

\footnotetext{
$4 \mathrm{Xi}$ stresses importance of The Communist Manifesto. Xinhua. http://www.xinhuanet.com/english/2018-04/24/c_137134028.htm. Acesso em 17/08/2018.

5 Sobre isso ler Rangel ([1959] 2005) e Castro (2014).
} 
da lei de Say, quanto dos modelos neoclássicos de equilíbrio geral. Keynes e a Gosplan soviética tornaram-se dupla face de uma mesma moeda. Segundo Rangel ([1957] 2005, p. 291):

O homem, nos dois casos, intervindo conscientemente na história, procura obter pelo planejamento o que antes se fazia por si, pois a sociedade que não garantir essas condições entra e crise e perece ${ }^{6}$.

Tendo em vista o paralelismo histórico, acrescido da dificuldade de se encontrar uma saída à presente crise sistêmica do capitalismo, o objetivo deste artigo é demonstrar que a transformação do "socialismo de mercado" em uma NFES vai além de um fenômeno localizado na China ${ }^{7}$. Trata de uma nova economia que o processo histórico está desenhando em meio, e a partir, do processo de financeirização, agressividade imperialista, do surgimento/espraiamento de novos paradigmas produtivos e tecnológicos e das novas e superiores formas de planificação sendo gestadas e executadas em larga escala na China ${ }^{8}$.

A nosso ver este processo de transição e mudança de MP dominante demanda a construção, do que chamamos de uma Nova Economia do Projetamento. O ponto de partida é o materialismo histórico de Marx e Engels acrescido de todo acervo teórico já existente elaborado ao longo do tempo pelo campo da heterodoxia econômica. Trata-se de uma exigência que a história coloca aos economistas, pois a própria ciência econômica muda e varia com o MP que, por seu turno, está em constante transformação.

Além desta introdução, o artigo se divide em outras quatro seções. Na seção 2, ao apresentaremos a visão de Ignacio Rangel apresentando os dois ramos da curva evolutiva da economia e seu duplo caráter evolutivo como forma tanto de justificar quanto de demonstrar elementos de validação teórica à nossa hipótese

\footnotetext{
${ }^{6}$ Qualquer semelhança com os consensos criados pelo Consenso de Washington e a consolidação da financeirização como a dinâmica de acumulação não terá sido mera consequência. A crise do paradigma no planejamento e do papel do Estado no ciclo econômico tem levado sociedades inteiras ao caos e a barbárie.

7 Sobre a noção do "socialismo de mercado" como uma Nova Formação Econômico-Social ler Gabriele \& Schettino (2012) e Jabbour \& Dantas (2018).

8 Concebemos as "novas e superiores formas de planificação econômica" que estão gestadas e executadas na China como instrumentos de maximização da ação do Estado sobre o território amparadas pela relação entre 1) a herança de planificação central da era maoísta; 2) instituição - ao longo das reformas econômicas - de mecanismos de ação estatal que vão da instalação de mecanismos de controle de fluxos de capitais externos e transformação da taxa de câmbio em bem público, planificado e de Estado (Jabbour e Dantas, 2017, p. 794); 3) a transformação do Estado em "empreendedor-em-chefe" a partir da indução ao surgimento de mecanismos de coordenação e socialização do investimento (Jabbour e Paula, 2018) e 4) internalização e utilização máxima, para fins de planificação de todo aparato anexo aos paradigmas produtivos e tecnológicos contemporâneos, notadamente o "Big Data".
} 
quanto da necessidade da construção de uma Nova Economia do Projetamento. Na seção 3 desenvolveremos as principais transformações em andamento no mundo. A seção 4 será dedicada a análise das condições que propiciaram a formação da Nova Economia do Projetamento. Ao final apresentaremos algumas conclusões.

\title{
2. ELEMENTOS DE VALIDAÇÃO TEÓRICA: OS CICLOS LONGOS E O DUPLO CARÁTER EVOLUTIVO DA ECONOMIA
}

\begin{abstract}
Não obstante, a história do desenvolvimento capitalista apresenta duas etapas muito bem definidas. Uma em que o sistema tende espontaneamente a, por meio de flutuações cíclicas, produzir mais procura efetiva do que oferta. (...). Outra em que a tendência espontânea do sistema é para a estagnação (...). Toda a problemática econômica muda quando passamos de uma etapa a outra, mudando também o equipamento científico adequado. Os economistas "clássicos" estudaram precipuamente os problemas de uma economia cujo produto se limita pelo lado da oferta. Os "modernos" (keynesianos e neoclássicos - estes no nível da "firma" e aqueles no "global") voltam-se especialmente para os problemas da procura (...). Se ampliarmos um pouco a perspectiva histórica, para abarcar o período anterior ao capitalismo - uma produção baseada no artesanato, na 'pequena produção' não capitalista de mercadorias quanto o que o sucede - o socialismo - encontraremos duas situações que, díspares de todos os pontos de vista, têm isto de comum: que, como na situação descrita pela lei de Say, a oferta e a procura tendem a tornarem-se efetivas no mesmo momento e são iguais. (Ignacio Rangel, [1956] 2005, p. 237).
\end{abstract}

Não foi por acaso acolher Ignacio Rangel como o autor que referencia este trabalho. Curiosamente, e paradoxal, apesar de ser reconhecido como "provavelmente o mais original analista do desenvolvimento econômico brasileiro" (Bresser Pereira e Rego, 1993, p. 98), trata-se de um autor ainda pouco lido e discutido pelo grande público interessado em temas brasileiros, incluindo os economistas (Jabbour, 2017, p. 562). Rangel levou às últimas consequências a crítica demonstrada por Marx à Economia Política, onde o autor alemão provou que as categorias básicas da Economia Política eram históricas e não universais; o que era puramente econômico tornava-se relativo à sua época particular e transitório. Voltando a Rangel, segundo Castro (2014, p. 203):

A originalidade da análise da obra de Rangel - marca reconhecida pelos comentadores do autor - é o resultado de ecletismo teórico desinibido e de uma profunda concepção historicista. Esta última derivada de sua visão marxista de mundo. 


\subsection{Da "estagnação secular" à Nova Economia do Projetamento}

Para fins de validação teórica de nossa proposta ao menos dois elementos da obra rangeliana são fundamentais. Mais acima relacionamos as transformações no campo da economia do século XX como produto da curva descendente do capitalismo. O eixo estruturante de toda obra de Rangel foi a noção da "dualidade básica" como um modo de produção complexo cuja evolução e os efeitos sobre a determinação dos investimentos e a produtividade do trabalho seriam reflexos das fases ascendente e descendente inerentes aos ciclos longos de Kondratiev ${ }^{9}$, notadamente as transformações sistêmicas resultantes da fase descendente do ciclo ${ }^{10}$. Segundo Rangel (1988, p.2) ${ }^{11}$ :

Ora, os ciclos econômicos não são apenas fatos econômicos. São fatos sociais no mais alto sentido dessa expressão. Noutros termos, além ele econômicos são, também, fatos jurídicos, políticos e até éticos e estéticos. Quem poderia, por exemplo, negar correlação entre nossa Semana de Arte Moderna e a "fase b" do $3^{\circ}$ Ciclo de. Kondratiev que estava começando? A "fortiori", como pôr em dúvida que o comportamento do Estado - e em geral os fatos políticos, como o Levante dos 18 do Forte tenha muito que ver com o mesmo fato conjuntural ${ }^{12}$

\footnotetext{
9 Segundo Pereira (2014, p. 548): (...), Rangel incorporou o conceito de ciclo longo à tese da dualidade. Nesse sentido, resgatou a teoria dos ciclos longos do economista russo Nikolai Kondratieff, desenvolvida por volta dos anos 1920. Os ciclos de Kondratieff tem duração aproximada de meio século, dividido em um quarto de século na fase "a", ou ascendente, e outro quarto na fase "b" ou descendente. Segundo Rangel (1985), citando Schumpeter, os ciclos não são, como as amígdalas, coisas que podem ser separáveis do corpo [...]. Sobre o papel dos ciclos de Kondratiev na obra de Rangel, ler: Silva (2009); Tolmasquim (1991); Mamigonian (1987) e Bresser-Pereira (1994).

10 Em Mamigonian (1993, p. 5): Note-se que se o 1ํ, $3^{\circ}$ e $5^{\circ}$ Kondratieff se abrem como revoluções industriais, o $2^{\circ}$ (1948-73, fase expansiva) e o $4^{\circ}$ (1948-73, fase expansiva) se abrem como revoluções nos transportes, com aplicações de invenções já realizadas nas revoluções industriais voltadas agora a este setor de circulação e a expansão da anterior revolução industrial em novas regiões geográficas: EUA e Alemanha entre 1848-73, e Europa e Japão entre 1948-73. Em momento posterior, assinalou Mamigonian (1999, p. 155): Os períodos depressivos (...) correspondem a mudanças profundas de conjunturas econômicas, políticas, sociais e espaciais. Assim a conjuntura depressiva 1920-1948 provocou nova relação mundo-nações: a Inglaterra abandonou definitivamente o livre-cambismo e houve fechamento dos mercados nacionais nos EUA, Alemanha, França e na periferia do sistema capitalista (substituições de importações se aceleraram).

11 No mesmo artigo Rangel, em passagem posterior, exercita seu sofisticado historicismo: Reciprocamente, o fato de ser a sociedade, o homem, o reino de uma história suscetível de ser escrita em tempos mensuráveis em nossas vidas, não quer dizer que ela também não comporte ciclos, como os da natureza. Ora, assim como os naturais, os ciclos sociais não excluem a história. Esta se escreve através deles.

12 Muitos outros fatos relacionados à fase descendente do ciclo poderiam ser elencados. Trata-se de uma "quase lei" sistêmica esta relação.
} 
Resumindo, os ciclos de Kondratiev é o primeiro elemento de validação teórica à nossa proposta. Afinal, não se trata de mera coincidência a ocorrência simultânea entre dois fenômenos contemporâneos: 1) a admitida possibilidade, por alguns economistas, de o sistema capitalista adentrar numa chamada, por Alvin Hansen no final da década de 1930, estagnação $\operatorname{secular}^{13}$ e 2) a consolidação da China, como expressão atual da, chamada por Rangel, Economia do Projetamento como o núcleo do novo centro do sistema. Michel Aglietta, discordando da possibilidade da estagnação secular vai mais longe ao apontar que o novo ciclo de inovações terá a China como palco central, segundo ele (2016, p. 124):

A revolução industrial que será necessária para mitigar os danos ambientais e adaptar habitats hostis envolveria bens públicos transnacionais, investimentos pesados e instituições para lidar com novos riscos sistêmicos. A China não só tem uma necessidade aguda, mas também os recursos financeiros e a vontade política de alocar grandes reservas de poupança para essa prioridade suprema.

A mensagem de Aglietta guarda grande sentido. O grau de socialização $e$ coordenação do investimento (Jabbour e Dantas, 2017) alcançada pelo país acrescida de sua capacidade de seu Partido Comunista de, ciclicamente, lançar mão de verdadeiras ondas de mudanças institucionais (Paula e Jabbour, 2018) garantindo assim "soluções de continuidade" ao seu desenvolvimento sugere razão à hipótese do economista francês.

\subsection{Um chamado à reflexão}

À guisa de uma reflexão inicial, lançamos três questões/obstáculos que o presente histórico demanda superação: 1) a teoria econômica, existente e acumulada ao longo do tempo, per si tem conseguido ir além da explicação da crise e da conjuntura, mas também de evoluir a ponto de demonstrar rumos concretos à solução dos atuais e graves problemas que assolam a humanidade? 2) devemos nos conformar com a forma, e suficiência, que as teorias existentes têm tratado as questões da contemporaneidade? e 3) Não seria verdade que a heterodoxia tem passado por uma crescente aproximação teórica e metodológica com a ortodoxia, a

\footnotetext{
${ }^{13}$ Sobre a hipótese em torno da estagnação secular, ler: Summers (2014) e Gordon (2016). A nosso ver a superação da presente crise deveria passar por mudanças qualitativas no âmbito da superestrutura de países como os EUA. O que não está ocorrendo. O caminho trilhado pela financeirização até a crise não foi mudado. Continua tudo como estava e que levou o mundo à uma crise de ainda imensuráveis proporções.
} 
partir de seu afastamento crescente da abstração, da visão de processo e da lição deixada por Visconde de Mauá - que reivindicava a para o bom senso nacional a missão de corrigir e completar a ciência de sua época (Rangel, 2005, p. 288) como elementos basilares da ciência voltada à transformação da realidade, perdendo assim capacidade crítica?

O chamado à reflexão que as questões acima colocadas têm variado sentido. A primeira delas é a de sugerir que o objetivo da ciência é evidenciar e por em equação a força das circunstâncias. É valido lembrar que a ciência, natural ou social, ao longo de sua evolução fora se tornando crescentemente histórica. Logo, valendo à análise de certas circunstâncias enquanto as mesmas perdurarem. Somente esta reflexão seria suficiente para demonstrar nossa inquietude diante da (in) capacidade das ciências sociais, no geral, em equacionar a força das circunstâncias. Seria somente um déficit de pensamento crítico ou algo mais profundo que se resume a resistir às próprias forças das circunstâncias? Neste caso, não se trataria de uma novidade. Seria apenas a repetição de uma história recente. Por exemplo, sobre a resistência às evidências que desmentiam os postulados da "globalização". Segundo Fiori (1997, p. 88-89):

(...) a própria resistência acadêmica à evidência dos fatos também pode ser atribuída ao fato de que este seja mais um daqueles momentos históricos em que a intensificação das lutas distributivas acaba submetendo o mundo acadêmico ao "pensamento vulgar" como já percebera Marx no seu comentário sobre a passagem da 'economia política clássica' para a 'economia vulgar' (...)

Sendo históricas e válidas somente enquanto perdurarem determinadas circunstâncias, não se trata de uma aforia a proposição de uma nova síntese teórica que nos condicione a dar cabo às já referidas forças das circunstâncias. Por outro lado, é inegável o afastamento da heterodoxia econômica frente a problemáticas que envolvem o reconhecimento e centralidade não somente da Questão Nacional, mas de noções para quem os Estados Nacionais deixaram de serem os verdadeiros donos dos cordéis no mundo. A força de noções globalizantes afetou diretamente o debate sobre a centralidade do Estado Nacional em prol de pautas pós-modernas, fragmentárias e, acima de tudo, a-históricas. Afora o preconceito aberto e indisfarçável em relação à China. Não foram poucos os acadêmicos brasileiros (sobretudo nas áreas relacioandas às ciências humanas e sociais) que seguiram às universidades do Atlântico Norte nos últimos 30 anos. Os asiáticos, sobretudo 
chineses, fizeram este mesmo percurso. Com uma diferença: como homens e mulheres de Estado voltadas às áreas, de forma geral, relacionadas às engenharias.

\subsection{A ciência econômica e seu duplo caráter evolutivo}

Pode parecer démodé, numa época em que a ciência, no sentido totalizante do termo, tem sido reduzida a uma lógica de mera especialização, utilizar a concepção da historicidade das leis da ciência para fins de justificar algo no campo do conhecimento sob as hastes de um encontro entre a filosofia e a ciência econômica. Vai além de uma forma de construir determinada hipótese. É uma forma de resistência ao que Milton Santos (1988 [2008], p. 18) chamou de "mundialização perversa e perversão das ciências".

Voltemos a Ignacio Rangel, que sob a influência de Kant demonstra que sendo a economia uma ciência social, matéria histórica por excelência, consequentemente, é sensível a um duplo processo evolutivo. Em suas palavras (Rangel, [1956] 2005, p. 204):

A economia é uma ciência histórica por excelência - qualidade que partilha das outras ciências sociais. Quer isso dizer que está submetida a um duplo processo evolutivo: o fenomenal e o nomenal. $\mathrm{E}$ quer dizer também que, ao contrário das ciências da natureza, especialmente as da natureza não viva, não pode ser estudada senão nesse duplo contexto.

Tendo como pressuposto o caráter histórico e, consequentemente, o duplo caráter evolutivo da ciência econômica, os limites de fronteira com os desígnios da "economia vulgar", tornam-se mais claros. Para Rangel ([1956] 2005, p. 204-205):

O conceito vulgar admite explicitamente apenas a evolução fenomenal da economia. Cada nova teoria surge como resultado de uma representação mais precisa da realidade transcendente, a qual, explicitamente, permaneceria sempre igual a si mesma. Assim a análise smithiana seria, em comparação com a fisiocrática, apenas uma representação mais perfeita, que considera certas facetas que Quesnay e seus amigos uniria a análise neoclássica à clássica, a keynesiana à neoclássica.

Em contraponto à perspectiva "vulgar", vaticina Rangel ([1956] 2005, p. 205):

Se admitirmos que a economia, além dessa evolução "fenomenal" (como representação, como ideia da coisa, como 'coisa para nós', no sentido kantiano), é também susceptível de outra evolução (a evolução "nominal" como objeto, coisa representada, 'coisa em si') seremos levados a uma atitude 
mais respeitosa para com o que os antigos pensaram. Esse pensamento seria talvez prejudicado pelas claudicâncias do método, pelo instrumental imperfeito de análise, mas continha uma espécie de verdade que não passou às teorias mais recentes pelo simples fato de que refletia uma realidade que deixou de existir, que se transformou, por seu próprio impulso interno noutra realidade.

Propor uma Nova Economia do Projetamento que espelhe o complexo de transformações que o mundo está atravessando não seria uma novidade diante de uma crise do sistema digna da questão levantada por Elizabeth II, em reunião com economistas na London School. A pergunta era simples: "Por que ninguém se deu conta?". A resposta, um verdadeiro ataque à inteligência alheia, veio três dias depois e assinada pelos professores Tim Besley e Peter Hennessy. Segundo ambos, a não previsão do que viria foi fruto de "uma falha da imaginação coletiva de muita gente brilhante", que não conseguiu "compreender os riscos do sistema em sua totalidade"14.

O outro lado da moeda desta explicação acima está contido, por exemplo, em livros como o lançado em 2017 por Richard Bookstaber (The End of Theory: Financial Crises, the Failure of Economics, and the Sweep of Human Interaction). Certamente em algum momento da vida Bookstaber acreditou em "concorrência perfeita", "neutralidade da moeda", "mão invisível", "expectativas racionais" etc. Mais uma prova da dificuldade de se perceber em meio ao mundo real.

De nossa parte não existe o "fim da teoria". A história explica, por exemplo, a relação entre o aumento da oferta da mão-de-obra, tornando-a quase inelástica, e o fim dos postulados clássicos que supunham a elasticidade eterna da mão-de-obra. O keynesianismo tomou o lugar dos neoclássicos que herdou dos clássicos a "lei dos mercados", justamente quando a procura efetiva deixou de refletir o fluxo de pagamentos aos fatores.

De crise em crise foram-se formando elementos que capacitariam o homem a deixar de ser "escravo das circunstâncias" para se tornar o próprio criador de fatores. A Revolução Russa inaugurou as condições institucionais a isso ao permitir que a demanda efetiva se tornasse cada vez mais independente do preço dos fatores. O planejamento econômico desde então entrara na ordem do dia.

Enfim, o que está ocorrendo é mais um movimento onde "se morre a coisa em si e para si". Resumindo: estão postas as condições ao surgimento de algo novo, uma teoria à altura da complexidade do mundo. O fenômeno chinês visto tanto em

\footnotetext{
${ }^{14}$ A carta de explicação esta disponível em http://www.feed-charity.org/user/image/besley-hennessy2009a.pdf
} 
conjunto quanto no detalhe diz muita coisa, inclusive sobre o surgimento currente calamo de novas formas de abordagem no campo da teoria.

\section{O MUNDO EM CONTINUA METAMORFOSE}

A NFES, e a nova economia que dela surge, se desenvolvem em um mundo caracterizado pelo cruzamento entre a financeirização como dinâmica de acumulação hegemônica e a dificuldade de se encontrar uma saída da grande crise do sistema iniciada em 2007-2008 criando uma situação de cada vez maior contestação à ordem criada pós-fim do Acordo de Bretton Woods. A ordem unipolar surgida com o fim da Guerra Fria - na qual o vértice do poder mundial são os Estados Unidos - também entra num processo de declínio tendendo à multipolarização.

\subsection{Entre a transição sistêmica e os novos paradigmas produtivos/ tecnológicos}

Tal situação vem plasmando um sistema de poder mundial em transição, com o advento de novos polos de poder que surgem da periferia do sistema internacional, fora do centro capitalista-imperialista mundial. Ainda no campo da análise geopolítica, Rabelo (2017) chama a atenção à existência de uma ordem onde o "velho" ainda guarda hegemonia e força:

Nesse quadro de profundas alterações na ordem mundial com a dominância neoliberal e novas formas de submissão neocolonial -, a ação imperialista, com seus empreendimentos combinados, impõe um poderoso domínio estrutural que os países da periferia do sistema mundial não conseguem atingir e muito menos suplantar. Mesmo o ciclo progressista na América Latina, iniciado em fins de 1990, não tem ameaçado esse domínio estrutural.

Transformações revolucionárias estão ocorrendo no campo da esfera produtiva com o processo de espraiamento/surgimento de novos paradigmas tecnológicos, processo este comumente chamado de $4^{\text {a }}$ Revolução Industrial, criando um novo padrão de manufatura com impactos sobre o mundo ainda inimagináveis ${ }^{15}$. Segundo Coutinho (2018):

${ }^{15}$ Sobre as consequências deste processo de transformação no campo da tecnologia, ler Coutinho (2018). 
A indústria do futuro fará parte dessa imensa rede digital global em processo de formação. A automação industrial será articulada pela internet englobando todas as cadeias produtivas desde o suprimento de matérias-primas, insumos, partes e subconjuntos, passando pelos processos de manufatura, distribuição, comercialização e chegando até os consumidores. A possibilidade de virtualizar, on-line ou em tempo real, o funcionamento de cadeias inteiras, através de sistemas avançados de computação, permitirá otimizar significativamente a eficiência e a produtividade. (...). Este novo padrão de manufatura conectada e inteligente também usufruirá de notáveis avanços na robótica e na chamada manufatura aditiva (impressão em 3D). As máquinas, equipamentos, robots, impressoras 3D ganharão capacitações cognitivas próprias, com base nos avanços da Inteligência Artificial (IA). Com efeito, a digitalização conectada das redes de produção propiciará a acumulação de dados em grande escala (a chamada Big Data).

Desta forma, repetindo, estamos diante de um processo histórico onde a economia da NFES está sendo desenhada a partir da síntese entre o processo de financeirização, agressividade imperialista, novos paradigmas produtivos e tecnológicos (abrindo amplos desafios e possibilidades à planificação) e das novas e superiores formas de planificação sendo gestadas e executadas em larga escala na China.

\subsection{O capitalismo e seu "Novo Medíocre Ocidental"}

De volta à história, é de bom grado expor uma definição exata do que se convencionou chamar de financeirização e sua expressão como o presente padrão de acumulação do sistema. Segundo Braga (1997, p. 195):

No capitalismo contemporâneo, segundo nossa hipótese, a financeirização é o padrão sistêmico de riqueza que se originou nos anos 60, a partir dos Estados Unidos, e se difundiu mundialmente, nas últimas décadas, provocando grandes instabilidades não apenas no país de origem, mas também no paradigma produtivista que foi, até há pouco, o "capitalismo organizado" japonês.

Impossível separar o fenômeno do novo padrão de acumulação com a reafirmação da hegemonia norte-americana ${ }^{16}$ e a "globalização" como ideia-força liberal lançada no início da década de 1990 cujo objetivo implícito estaria em mostrar que, enfim, segundo Fiori (1997, p. 87):

\footnotetext{
${ }^{16}$ Sobre a então retomada da hegemonia norte-americana, ler Tavares (1985 e 1997) e Rangel (1983).
} 
Haveria chegado a hora, finalmente, em que a livre circulação de capitais, a despolitização dos mercados, a gestão autônoma da moeda e o livre comércio entre os povos transformaram em fato o ideal sonhado por Dudley North, em 1691, "de que o mundo inteiro não fosse mais do que um só povo, ao interior do qual as nações fossem como pessoas".

Tão interessante, quanto contraditório, a supremacia do capital financeiro tem sido elemento nodal de uma nova onda de concorrência, seguida de generalização de outra etapa diretamente ligada à reconcentração e recentralização dos blocos de capital. O pano de fundo desse fenômeno é a intensificação da rivalidade intercapitalista. Belluzzo (2009, p. 94) desvela uma determinada falácia amplificada pela "globalização":

Para escândalo dos liberais, a grande empresa que se lança à
incerteza da concorrência global necessita cada vez mais do
apoio dos Estados nacionais dos países de origem. O Estado
está cada vez mais envolvido na sustentação das condições
requeridas para o bom desempenho das suas empresas na
arena da concorrência generalizada e universal. (...) dependem
do apoio e da influência política de seus Estados nacionais
para penetrar em terceiros mercados (...), não podem
prescindir do financiamento público para suas exportações nos
setores mais dinâmicos e seriam deslocadas pela concorrência
sem o benefício dos sistemas nacionais de ciência e
tecnologia.

São notórias as promessas não cumpridas pela "globalização", entre elas a do crescimento econômico como consequência de todo tipo de desregulamentação sobre os fluxos de capitais, por exemplo. Ao contrário, o mundo nunca experimentou, desde 1997, tantas crises financeiras em tão pouco tempo. A instabilidade é uma regra geral do sistema. A crise financeira aberta em 2008 aprofundou este traço sistêmico, produzindo o que o economista inglês John Ross (2017) chamou, de "Novo Medíocre Ocidental", onde o crescimento econômico, sobretudo do G-7, não voltaria, tão cedo, a patamares anteriores. Para título de exemplo, segundo Ross (2017):

Over a five-year period, annual average growth in the G7 economies is projected by the IMF to fall from $3.1 \%$ in 2000 to $1.6 \%$ in 2022.

Over a ten-year period, annual average growth in the G7 economies is projected by the IMF to fall from $2.9 \%$ in 2000 to $1.7 \%$ in 2022.

Over a twenty-year period, annual average growth in the G7 economies is projected by the IMF to fall from $2.9 \%$ in 2000 to $1.5 \%$ in 2022. 
A situação é mais alarmante na medida em que uma comparação histórica é feita, nos lembra Ross (2017):

The fall in output after 1929 was far more severe than after 2007 - the maximum fall in G7 GDP after 1929 was $17.5 \%$ compared to $4.0 \%$ after 2007 . However, after the initial severe downturn, overall growth in the G7 economies in the period after 1929 was far more rapid than after 2007. The cumulative result is that by 10 years after the initial crisis overall growth in the G7 economies after 1929 was $15.9 \%$ compared to only $10.9 \%$ after 2007 . This means that by the end of 2017 overall growth in the G7 economies, after the international financial crisis, will actually be slower than during the 'Great Depression'.

O que fica evidente com os dados apresentados é que não somente o capitalismo tem dado sinais de certo esgotamento. As "novas teorias" que surgem para substituir o keynesianismo e dar solução à crise de 1973 tem como principal assertiva a massificação de uma falsa oposição entre Estado e mercado (BresserPereira, 2009, p. 6) com o objetivo de dar legitimidade teórica a um corpo de ideias forjadas para elevar ao grau de "ciência" o circuito D-D' e o próprio poder norteamericano. Os resultados não poderiam fugir de uma catástrofe política, social e econômica como a que vivenciamos hoje.

O oposto ocorre na China. Segundo Jabbour e Paula (2018, p. 3):

O processo de desenvolvimento econômico chinês é um dos fenômenos mais impressionantes do mundo em que vivemos, em função tanto da sua longevidade quanto no seu alcance interno e externo: o crescimento médio do Produto Interno Bruto (PIB) nos últimos 35 anos foi de 9,5\% a.a., ao mesmo tempo em que a renda per capita no período passou de US\$ 250 em 1980 para US\$ 9.040 em 2014. Por trás desse processo, há de se destacar a alta relação investimento/PIB (45,6\% em 2015), suas imensas reservas cambiais (US\$3,1 trilhões em dezembro de 2016) e enorme volume de comércio externo $(35,9 \%$ do PIB). É na história por trás desses dados que reside tanto a formação, na China, de uma "tripla condição" de potência comercial, industrial e financeira, quanto a privilegiada posição política e geopolítica de maior credora líquida do mundo (US\$1,97 trilhão ou $20,8 \%$ do PIB, em março de 2015).

\section{FINANCEIRIZAÇÃO X NOVA ECONOMIA DO PROJETAMENTO}

This is what socialism with Chinese characteristics entering a new era means: The Chinese nation, which since modern times began had endured so much for so long, has achieved a tremendous transformation. (...). It means that scientific socialism is full of vitality in 21 st century China, and that the banner of socialism with Chinese characteristics is now flying 
high and proud for all to see. It means that the path, the theory, the system, and the culture of socialism with Chinese characteristics have kept developing, blazing a new trail for other developing countries to achieve modernization. It offers a new option for other countries and nations who want to speed up their development while preserving their independence; and it offers Chinese wisdom and a Chinese approach to solving the problems facing mankind (Xi Jinping, 2017) $)^{17}$

\subsection{Sobre o "milagre"}

É muito comum atribuir como um "milagre" o desempenho econômico chinês nos últimos 40 anos. Eis a questão: só atribuímos algo como um milagre quando as teorias presentes não conseguem explicar determinado fato ou fenômeno. Se existe algo que as teorias em curso são incapazes de decifrar, isso significa que alguma inovação teórica está em andamento. Segundo Lin Yifu (2017):

Sabemos que há inovação teórica porque as teorias existentes não podem explicar novos fenômenos. O fenômeno que a China começou com a reforma e abertura em 1978 pode ser considerado um milagre na história da economia humana. As pessoas pensam que é um milagre porque não pode ou é difícil de explicar com as teorias existentes ${ }^{18}$.

Em artigo publicado na Monthly Review, nos chamou a atenção a seguinte referência que sugere não somente que as teorias em voga são incapazes de explicar o fenômeno. Uma das consequências do processo de desenvolvimento no país é o surgimento de novas teorias no campo da Economia Políticas, conforme Enfun e Xiaoqin (2017):

China's rapid economic development in recent years is often characterized as "miraculous". (...). But as we have written elsewhere, "theoretical problems have started to emerge with regards to the very existence, content, and prospects of the China model."The key question, then, is what kind of economic theory and strategy underpin this "miracle. China's model has been variously described as a form of neoliberalism, or as a novel kind of Keynesianism. Against these positions, we hold that the country's major recent developmental gains are the achievements of theoretical advances in political economy, originating in China itself $(\ldots)^{19}$.

\footnotetext{
17 Ênfases nossas.

18 Traduzido da versão em chinês.

19 Ênfases nossas.
} 
Tomando o nomeno intrínseco a um processo desta natureza não poderíamos deixar de salientar que:

1) O limite das teorias atuais, quando aplicadas ao caso chinês, fica explicito na incapacidade de conceber o processo partindo do pressuposto de se tratar de uma formação social complexa, onde o antigo e o moderno coabitam com suas respectivas institucionalidades. Por exemplo, modelos e modelagens de qualquer tipo ou forma não são instrumentos adequados que, no melhor dos casos, demonstre uma pequena parcela da verdade, não sua totalidade - visível somente na análise do processo histórico;

2) É evidente que uma teoria, além de um atributo da historicidade das leis da ciência, guarda muitas das verdades contidas nas teorias anteriores. Além disso, uma teoria é expressão da relação de causa e efeito entre variáveis históricas de cunho socioeconômicas, como as diferenças históricas de nível de desenvolvimento entre diferentes regiões;

3) Uma Nova Economia do Projetamento que surge é prova de que tudo flui - no campo da coisa representada como no campo da representação da coisa. Rangel ([1956] 2005, p. 204-205). O "milagre" chinês, neste sentido, torna possível o surgimento de novas teorias correspondentes ao fenômeno. Como por exemplo, o comportamento de uma economia planificada diante da fase descendente do ciclo ou qual o grau de distorção sofrida pela lei do valor em uma economia dominada por empresas públicas etc;

4) A admissão do desenvolvimento econômico como um processo marcado do salto de um desequilíbrio a outro é essencial no processo de construção de novas teorias. A rigidez de pensamento não conceberia jamais o que Albert Hirshman nomeou de "racionalidades ocultas" (1984, p. 98), ou seja, a existência de possibilidades que escapam aos modelos e teorias gerais. Essa concepção cabe perfeitamente ao caso chinês ${ }^{20}$;

Por fim, o "bom senso nacional" já aludido mais acima nos leva a acreditar que no caso de um Estado milenar como a chinesa, nenhuma teoria estaria dispensada de adaptação. Esse senso de formação social foi reiterada por Lin Yifu (2012, p. 66):

20 Um exemplo de "racionalidade oculta" está na probabilidade de o crescimento chinês tenha como fator primário, percebido por Deng Xiaoping, a existência de recursos ociosos na agricultura do que pela chamada "poupança". 
(...) We can never be too careful when it comes to the application of a foreign theory, because with different preconditions, no matter how trivial they seem, the result can be very different.

\subsection{A luta de ideias e as condições criadas ao surgimento da Nova Economia do Projetamento}

Longe de um exercício diletante, o chamado à construção de uma Nova Economia do Projetamento assentada, principalmente, na transformação do "modelo chinês" em uma NFES guarda caráter político estratégico. É parte essencial, verdadeira exigência, da luta de ideias travada entre os cães de guarda da grande finança de um lado e os progressistas de todas matizes de outro. Não se trata de um ciclo descendente como os anteriores. O ciclo atual, como já apontado mais acima por Rabelo, ainda ocorre sob dominância neoliberal e um imperialismo capaz de impor um poderoso domínio estrutural. É ilusão acreditar numa derrocada rápida da hegemonia norte-americana.

A Nova Economia do Projetamento que surge na NFES chinesa já guarda universalidade. Como extensão renovada da Economia do Projetamento elaborada por Ignacio Rangel, é antítese ao neoliberalismo e alternativa ante a financeirização e suas formas de dominação sobre povos e países. Sua cristalização é fruto do processo histórico iniciado com as reformas econômicas (1978), onde desde então o país se transformou em um verdadeiro campo de experimentações. Afora alguns enunciados gerais, os clássicos do marxismo não deixaram nenhuma receita ou fórmula pronta à consecução da nova sociedade; exercitaram pouco a abstração neste campo. Segundo Deng Xiaoping (1984, p. 48)

What is socialism and what is Marxism? We were not quite clear about this in the past. Marxism attaches utmost importance to developing the productive forces. We have said that socialism is the primary stage of communism and that at the advanced stage the principle of from each according to his ability and to each according to his needs will be applied. This calls for highly developed productive forces and an overwhelming abundance of material wealth. Therefore, the fundamental task for the socialist stage is to develop the productive forces. The superiority of the socialist system is demonstrated, in the final analysis, by faster and greater development of those forces than under the capitalist system. As they develop, the people's material and cultural life will constantly improve. One of our shortcomings after the founding of the People's Republic was that we didn't pay enough attention to developing the productive forces. 
Socialism means eliminating poverty. Pauperism is not socialism, still less communism ${ }^{21}$.

O "Socialismo com características chinesas" é o sistema teórico que baseia o desenvolvimento do marxismo à luz das condições específicas da China. O ponto de partida foi o reconhecimento de que o país encontrava-se na etapa primária do socialismo, etapa esta cuja contradição principal reside no baixo nível de desenvolvimento das forças produtivas não somente em relação a si mesma, mas também em comparação tanto com os países capitalistas do Atlântico Norte, quanto aos seus dinâmicos vizinhos asiáticos.

O desenvolvimento das forças produtivas passou a ser o objetivo central do regime, algo que não estaria longe das seguintes observações de Marx e Engels, ([1848] 1998, p. 56):

O proletariado utilizará sua supremacia política para arrancar pouco a pouco todo capital à burguesia, para centralizar todos os instrumentos de produção nas mãos do Estado, isto é, do proletariado organizado em classe dominante, e para aumentar, o mais rapidamente possível, o total das forças produtivas $^{22}$.

Ao assumir que a China encontrava-se na etapa primária do socialismo vai ao encontro do conceito de Marx sobre a possibilidade real de uma longa transição entre os dois MP's antagônicos. Além disso, é reabilitada uma das noções elaboradas pelos fundadores do socialismo científico para quem a propriedade privada por muito tempo será parte integrante do sistema, conforme Engels (1982, p. 57):

(...) do mesmo modo que não se podem fazer aumentar de um só golpe as forças produtivas já existentes tanto quanto é necessário para a edificação da comunidade. Por isso a revolução do proletariado, que com toda a naturalidade se vai aproximando, só a pouco e pouco poderá, portanto, transformar a sociedade atual, e somente poderá abolir a propriedade privada quando estiver criada a massa de meios de produção necessária para isso ${ }^{23}$.

A legalização da propriedade privada e da economia de mercado, na China, foi fator decisivo no que concerne à aproximação e o desenvolvimento de novas possibilidades no campo da evolução da teoria.

\footnotetext{
21 Ênfases nossas.

22 Idém

23 Ibidem
} 


\subsection{Toma corpo a Nova Economia do Projetamento}

Observando o processo histórico, podemos concluir que as reformas econômicas geraram uma síntese entre o Estado Revolucionário fundado em 1949 com a internalização, em 1978, do Estado Desenvolvimentista de tipo asiático. Segundo Castells (2001, p. 317):

China's economic development and technological
modernization, within the framework of the new global
economy, were (are) pursued by the Chinese communist
leadership both an indispensable tool for national power, and as
a new main legitimacy of the Communist Party. In this sense,
Chinese communism in the early twenty-first century represents
the historical merger of the developmental state and the
revolutionary state

Trata-se de um bom ponto de partida o enunciado de Castells. Possibilita uma visão estratégica essencial na medida em que relaciona uma decisão política de vulto com uma das características do socialismo chinês: o papel do Partido Comunista da China (PCCh), utilizando uma feliz elaboração de Gramsci, o verdadeiro "Príncipe Moderno".

Por outro lado, ao se apresentar como um "modelo" de Estado Desenvolvimentista uma linha quase reta liga o materialismo histórico de Marx e Engels como ponto de partida e acrescido de todo acervo teórico já existente elaborado ao longo do tempo pelo campo da heterodoxia econômica: desde os clássicos da Economia Política (Smith e Ricardo), passando pelo institucionalismo de Thorstein Veblen, os "pioneiros do desenvolvimento" (Albert Hirschman, Gunnar Myrdal, Raúl Prebisch, Alexander Gerschenkron etc) pelas contribuições de dois economistas burgueses nada vulgares (Keynes e Schumpeter).

Certamente uma questão deverá ser levantada: não se trata de uma combinação teórica não somente eclética, mas, sobretudo contraditória? Acreditamos que não. Ao contrário, a utilização de diferentes autores e suas teorias é fator positivo à realização de uma análise abrangente e multifacetária tanto do processo de desenvolvimento chinês quanto da elaboração/exigência história de uma Nova Economia do Projetamento. Essa forma de abordagem já fora utilizada duas vezes, a primeira é refletida no enunciado abaixo (Paula e Jabbour, 2017, p. 47): 
periférico, cujas abordagens entendemos como complementares: Arthur Lewis e sua noção de desenvolvimento econômico com oferta ilimitada de mão de obra, que dada a enorme população rural existente na China tem uma óbvia aplicação ao caso chinês; Alexander Gershenkron e sua análise das especificidades históricas distintas do processo de industrialização retardatária, ao qual o sistema financeiro e o Estado desempenham um papel fundamental no processo de acumulação de capital; Albert Hirschman e sua análise do processo de desenvolvimento desequilibrado e suas possibilidades de encadeamento no processo de industrialização, se contrapondo a concepção de um desenvolvimento realizado por etapas definidas; e, por fim, Raul Prebisch e sua abordagem clássica da relação desigual centro-periferia, ao qual veremos a China como um exemplo de estratégia de desenvolvimento com vistas à superar sua própria condição periférica.

A segunda abordagem de tipologia semelhante sugeriu que (Jabbour e Paula, 2018, p. 4):

O desenvolvimento econômico na China pode ser explicado pelo surgimento cíclico de instituições que delimitam uma contínua reorganização de atividades entre os setores estatal e privado da economia. Neste sentido, a pronta reação chinesa à crise de 2009 demonstrou o patamar superior de ação do Estado, não somente no nível do controle da grande indústria e da grande finança, como também em elevado nível da "socialização do investimento". Para tanto, desenvolvemos uma abordagem analítica a partir das contribuições de John Maynard Keynes, Alexander Gerschenkron, Ignacio Rangel e Albert Hirschman, de modo a permitir um entendimento mais abrangente do processo de desenvolvimento chinês.

Tais autores têm em comum a rejeição a ideia de que o desenvolvimento econômico é um processo natural a ser alcançado pelas economias subdesenvolvidas e buscam entender as especificidades do processo do desenvolvimento tardio ou periférico, cuja dinâmica deve necessariamente ser induzida pelo Estado. Fica assim revelada o núcleo duro de uma Nova Economia do Projetamento; extensão da reinauguração da Economia do Projetamento.

\subsection{Entre a Nova Economia Estruturalista e a nossa "negação da negação"}

Não se trata de nenhuma inverdade que existem pontos de encontro entre a escola recém-surgida sob os auspícios do Banco Mundial sob o nome de "Nova Economia Estruturalista" 24 e a nossa proposta. Ambas têm herança de caráter

${ }^{24}$ Trata-se de uma agenda de pesquisa liderada pelo economista chinês Lin Yifu e composta, por exemplo, de economistas como Dani Rodrik, Ricardo Hausmann, Andres Velasco, Philippe Aghion, 
desenvolvimentista e se apoiam, em apenas alguns casos, nos "pioneiros do desenvolvimento". É nesse momento que se chega a uma fronteira que nos distingue, observe as seguintes palavras de Dani Rodrik sobre essa agenda de pesquisa e seu fundador, Lin Yifu (2011):

Justin Lin wants to make structuralist economics respectable again, and I applaud him for that. He wants to marry structuralism with neoclassical economic reasoning (...). The central insight of structuralism is that developing countries are qualitatively different from developed ones. They are not just radially shrunk versions of rich countries. In order to understand the challenges of under-development, you have to understand how the structure of employment and production (...) is determined and how the obstacles that block structural transformation can be overcome. The central insight of neoclassical economics is that people respond to incentives. We need to understand the incentives of, say, teachers to show up for work and impart valuable skills to their students or of entrepreneurs to invest in new economic activities if we are going to have useful things to say to governments about what they ought to do.

Dani Rodrik, continua:

To distinguish of structuralist development economics from oldstyle structuralism Lin writes that a key difference is that the old school advocated policies that go against an economy's comparative advantage. The new approach, by contrast, "stresses the central role of the market ... and advises the state to play a facilitating role to assist firms in the process of industrial upgrading by addressing externality and coordination issues." Lin argues that government policies should "follow" comparative advantage, rather than "defy" it.

O que seguiu acima é suficiente para distinguir as duas propostas. Em nosso caso, além de partir dos postulados clássicos do Materialismo Histórico, estamos a tratar de uma agenda de pesquisa que tem consciência que da junção entre a Economia Política inglesa, a filosofia clássica alemã e o socialismo utópico francês surgiu o socialismo científico. Sendo ciência, deve evoluir ao longo do tempo e da experiência no concreto, tirando lições e buscando saídas. O contato com outros aportes teóricos é forma de enriquecer e manter contato com o que nos é convergente. É muito diferente de uma apostasia como a proposta da "Nova Economia Estruturalista”. Apostasia, justamente por negar o próprio ponto de partida do estruturalismo original: demonstrar a falácia escondida na essência da lei das vantagens comparativas.

Michael Spence, Ann Harrison, Célestin Monga dentre outros. Sobre os aportes desta escola ler Lin (2012). 
Postura semelhante teríamos caso nos dispuséssemos a pagar o dízimo, cobrado pelo mercado de ideias, nos pronunciando contra as primeiras experiências socialistas (e propor uma "renovação" do marxismo e do "socialismo com face humana", agora sem as amarras do planejamento econômico com exceção a um chamado planejamento indicativo que, até onde sabemos, nunca ocorreu na China).

\section{CONCLUSÕES}

Em ao menos dois fatos podemos resumir o mundo hoje: 1) crise sistêmica sem sinal de superação no médio prazo e 2) a continuidade do maior e mais longevo processo de desenvolvimento na história. Há quase 40 anos a China cresce a uma média anual superior a 9\%. Não existe resposta fácil capaz de explicar as razões deste desempenho. O fenômeno deixou de ser uma repetição de um "modelo" já testado anteriormente e em outro país, tipo uma réplica tamanho gigante do "modelo" japonês. O tal "modelo" é uma construção histórica chamada de "economia socialista de mercado" cuja evolução recente, notadamente desde 2009, fez-se transformar em uma NFES 25 .

A complexidade desta NFES é seu principal atributo, pois implica se tratar de uma formação marcada pela convivência de diferentes estruturas/formações sociais. É nesta NFES que se assenta o "socialismo de mercado" como um modo de produção complexo. Por não se tratar de um modo de produção puro, o "socialismo de mercado" deve ser tratado como um fenômeno regido por combinações entre diferentes modos e relações de produção.

Completa esse quadro a própria financeirização como padrão sistêmico de geração de riqueza, a crescente agressividade imperialista, o surgimento/espraiamento de novos paradigmas produtivos e tecnológicos e das novas e superiores formas de planificação sendo gestadas e executadas em larga escala na China. Voltaremos a isso.

Algum tempo atrás duas ocorrências de ordem corriqueira. Em troca de ideias recente lembramos-nos de um livro muito esquecido escrito por Ignacio Rangel chamado "Elementos de economia de projetamento", lançado em 1959. Um de nós com sua sólida formação em microeconomia, apesar de ser marxista, fez menção a

${ }^{25}$ As características do processo recente chinês e a apresentação de alguns dos atributos do "socialismo de mercado" e suas formas originais de funcionamento já desenvolvida em Jabbour e Dantas (2017) e Jabbour e Paula (2018). 
algumas passagens do livro. O outro apenas disse que se trata do melhor livro escrito por Ignacio Rangel, que inicia o livro como um economista neoclássico e o encerra imaginando a formação de conglomerados empresariais fora do sistema de preços, ou seja: a formação de conglomerados sob uma formação social superior, o socialismo. Ignacio Rangel estava olhando pelo menos 50 anos à frente: sem saber ele estava vislumbrando justamente a forma como foram reorganizados os conglomerados empresariais estatais chineses no final da década de 1990. Nem a União Soviética que Rangel observava como um espelho do futuro esse tipo de organização empresarial ocorria.

Mas na verdade é o economista Márcio Henrique Monteiro de Castro quem chama a atenção à verdadeira intenção de Rangel contida no livro. Segundo Castro (2014, p. 202):

A leitura de seu conteúdo revela o objetivo do autor. Construir, a partir do acervo da ciência econômica, com todas suas escolas e distintas abordagens, uma teoria econômica da economia do projetamento, entendida esta como a economia que o processo histórico estava desenhando no século $X X$, a partir do capital financeiro, do keynesianismo e da planificação soviética.

A passagem abaixo espelha, de forma completa a personalidade e 0 inconformismo que assola a nós dois e que serviu de estímulo e coragem para transformar em palavras nossos sentimentos com a forma que os intelectuais brasileiros tem se comportado diante do quadro nacional e internacional. Nas palavras de Castro (2014, p. 202):

A ambição intelectual do livro (...) indica o incorformismo de Rangel com as teorias e interpretações existentes no trato das questões de sua contemporaneidade.

Nunca é demais lembrar que Rangel - de forma isolada e corajosa - travou uma batalha sem quartel contra o Plano Trienal de Celso Furtado. Isso num exato momento em que a CEPAL era algo próximo do incontestável. Como o marxista mais preparado surgido no país, Rangel sabia que o planejamento era incompatível no curto prazo. Até hoje os cepalinos/estruturalistas não entenderam que o capitalismo gera suas próprias restrições, mas tem que superar seus bloqueios de mercado. O preço pago por Rangel todos sabem: 0 isolamento intelectual e o exercício aberto de uma censura branca contra sua obra ${ }^{26}$.

\footnotetext{
${ }^{26}$ É muito comum encontrar alunos e/ou professores de economia que nunca ouviram falar ou, ao menos, já teve algum contato com a obra rangeliana.
} 
A China decide enfrentar os dissabores da crise financeira anunciando, em novembro de 2008, um pacote de investimentos da ordem de US\$ 600 bilhões a serem executados por imensas empresas estatais. Empresas tais forjadas em um processo de fusões e aquisições, no final da década de 1990, que resultou no surgimento de 149 conglomerados empresariais estatais. Dados suficientes para demonstrar que: 1) o país atingiu uma capacidade de coordenação e socialização do investimento inimaginável para qualquer país capitalista; 2) espantosa capacidade financeira de executar investimentos de qualquer ordem, fazendo base a novas e superiores formas de planificação econômica; 3) os conglomerados empresariais estatais conformam-se como o núcleo da consolidação da NFES.

Propomos, diante do quadro exposto, chamar ao desafio de se elaborar uma Nova Economia do Projetamento. Ao longo do artigo buscamos atentar às particularidades de nossa contemporaneidade e perceber algo interessante a partir do momento que se começam a classificar algo como um "milagre" duas verdades aparecem: as teorias existentes são incapazes de explicar o que ocorre e se ocorre, alguma teoria há de existir ou está em construção currente culamu. A nosso ver a Nova Economia do Projetamento é a economia que surge deste complexo, mas ainda se trata de uma caixa vazia. Sob as lentes do marxismo, chamamos e todas as correntes da heterodoxia econômica ao desafio. Está lançado o desafio.

\section{REFERÊNCIAS}

AGLIETTA, M. “America’s slow down”. New Left Review, 100: 119-128, 2016.

BRAGA, J. C. "Financeirização global - O padrão sistêmico de riqueza do capitalismo contemporâneo". In TAVARES, M, C, e FIORI, J.L. Poder e dinheiro. Petrópolis: Editora Vozes, 1997.

BRESSER-PEREIRA, L.: Assalto ao Estado e ao mercado, neoliberalismo e teoria econômica. Estudos Avançados. N. 23 (66), p. 1-17, 2009.

CASTELLS, M. End of Millenium - The Information Age: Economy, Society and Culture. New York: Wiley-Blackwell, 2001.

CASTRO, M. H. "Elementos de economia do projetamento". In HOLANDA, F, M.; ALMADA, J. e PAULA, Z. A. In Ignácio Rangel, decifrador do Brasil. São Luís: Edufma, 2014.

COUTINHO, L. A 4ํำ Revolução industrial: criativa ou disruptiva para o Brasil? Princípios. N. 150:30-38, 2018.

ENFU, C; XIAOQIN, D. A Theory of China's 'Miracle'. Monthly Review, v. 68, n 8, p. 12-23, January, 2017. 
ENGELS, F. "Princípios Básicos do Comunismo". In MARX, K e ENGELS, F. Obras Escolhidas. Lisboa: Editorial "Avante!", 1982. v. 1 p. 52-59

FIORI, J. L. "Globalização, hegemonia e império". Poder e dinheiro. Petrópolis: Editora Vozes, 1997.

GORDON, R. Is "US economic growth over? Faltering innovation confronts the six headwinds". NBER Working Paper, n. 18315, APRIL, 2012.

GABRIELE, A.; SCHETTINO, F. "Socialist market economy as a distinct Socio-Economic Formation internal to the modern Mode of Production". New Proposals: Journal of Marxism and Interdisciplinary Inquiry, v. 5, n. 2, p. 20-50, 2012.

JABBOUR E.; DANTAS, A. "The political economy of reforms and the present Chinese Transition”. Brazilian Journal of Political Economy, v. 37, n. 4, p. 789-807, 2017.

JABBOUR E.; DANTAS, A. "Na China emerge uma Nova Formação Econômico-Social". Princípios, № 154, p.70-86, 2018.

JABBOUR, E.; PAULA, L. F. "A China e a "socialização do investimento": uma abordagem Keynes-Gerschenkron-Rangel-Hirschman". Revista de Economia Contemporânea. N. 22 (1), p. 1-23, 2018.

Lin, J. Y. Demystifying the Chinese Economy. Cambridge UK: Cambridge University Press, 2012.

MARX, K; ENGELS, F. Manifesto Comunista. São Paulo: Boitempo, [1848] 1998.

MEIER, G.; SEERS, D. (ed.). Pioneers in Development. Oxford: Oxford University Press, 1994.

PAULA, L. F.; JABBOUR, E. A China e seu catching up: uma análise desenvolvimentista clássica. ABDE-BID: Rio de Janeiro, 2017.

RABELO, R. A nova luta pelo Socialismo. Fundação Maurício Grabois: http://www.grabois.org.br/portal/artigos/153888/2017-09-26/a-nova-luta-pelo-socialismo.

Access in 07/12/2017.

RANGEL, I. Uma crise e dois desafios. Rumos, p. 4-11, mar./abr. 1988.

RANGEL, I. "Desenvolvimento e Projeto". In, RANGEL, I.: Obras Reunidas. Rio de Janeiro: Contraponto, [1956] 2005.

RANGEL, I. "Dualidade Básica da Economia Brasileira”. In, RANGEL, I.: Obras Reunidas. Rio de Janeiro: Contraponto, [1957] 2005.

RANGEL, I. "Elementos de Economia do Projetamento". In, RANGEL, I.: Obras Reunidas. Rio de Janeiro: Contraponto, [1959] 2005.

RANGEL, I. “A recuperação americana”. Folha de S. Paulo, 21/04/1983.

RODRIK, D. "Comments on 'New Structural Economics' by Justin Yifu Lin". The World Bank Research Observer. v. 26, n. 2, p. 227-229, 2011.

ROSS, J. "The West's 'new mediocre' and the rise of China's economics. Learning from China". https://www.learningfromchina.net/blog/the-wests-new-mediocre-and-the-rise-ofchinas-economics. Acesso em 19/06/2018.

ROSS, J. “Deng Xiaoping and John Maynard Keynes”. Soundings. N. 46, p. 25-47, 2010. 
SANTOS, M. Metamorfose do Espaço Habitado: Fundamentos Teóricos e Metodológicos da Geografia. São Paulo: Hucitec, 1998.

SUMMERS, L. "US economic prospect: secular stagnation, hysteresis, and the zero lower bound". Business Economics, 49 (2): 65-73, 2014.

TAVARES, M,C. "A retomada da hegemonia norte-americana". Revista de Economia Política. V. 5, n. 2 (18), p. 1-11, 1985.

TAVARES, M. C. "A Reafirmação da Hegemonia Norte-Americana". In TAVARES, M,C e FIORI J.L. Poder e dinheiro. Petrópolis, Editora Vozes, 1997.

YIFU, L. (22/11/2017) 'The Arrival of the Century of Chinese Economics' https://www.guancha.cn/LinYiFu/2017_11_22_435941_2.shtml>. Acesso em: 15/07/2018

YIFU, L. New Structural Economics - A Framework for Rethinking Development and Policy. Washington DC: The World Bank, 2012.

\section{NOTAS DE AUTOR}

\section{CONTRIBUIÇÃO DE AUTORIA}

Elias Khalil Jabbour - Concepção. Elaboração do manuscrito, revisão e aprovação da versão final do trabalho Alexis Toríbio Dantas - Elaboração do manuscrito. Participação ativa da discussão dos resultados; Revisão e aprovação da versão final do trabalho.

Carlos José Espíndola - Elaboração do manuscrito. Participação ativa da discussão dos resultados; Revisão e aprovação da versão final do trabalho.

\section{FINANCIAMENTO}

Não se aplica.

CONSENTIMENTO DE USO DE IMAGEM

Não se aplica.

APROVAÇÃO DE COMITÊ DE ÉTICA EM PESQUISA

Não se aplica.

CONFLITO DE INTERESSES

Não se aplica.

\section{LICENÇA DE USO}

Este artigo está licenciado sob a Licença Creative Commons CC-BY. Com essa licença você pode compartilhar, adaptar, criar para qualquer fim, desde que atribua a autoria da obra.

\section{HISTÓRICO}

Recebido em: 24-10-2019

Aprovado em: 03-01-2020 